\title{
EL INVENTARIO DE BIENES DE UN ARTISTA NOVOHISPANO: EL ARQUITECTO JUAN MONTERO
}

\section{Martha Fernández}

Entre los aspectos de la vida de los artistas virreinales carentes de estudio se encuentra uno relacionado con el desenvolvimiento económico de la Nueva España: la canalización del producto de su trabajo. Cuando investigamos la vida de uno de esos artistas procuramos conocer las obras que realizó y, a través de manuscritos de la época, en ocasiones nos llegamos a enterar de lo que se le pagó por ellas; sin embargo, pocas veces logramos conocer la manera en la que aprovechó sus ganancias. La finalidad de este artículo es precisamente intentar una aproximación a ese tema por medio del análisis del inventario de bienes de un artista colonial muy versátil y activo: Juan Montero de Espinosa.

El documento fue localizado por la licenciada Raquel Pineda del Instituto de Investigaciones Estéticas de la UNAM, y se encuentra en el número 381 del ramo Bienes Nacionales del Archivo General de la Nación de México, marcado con el número 18.

Comencemos por saber quién fue Juan Montero: su perfil humano y su perfil artístico.

\section{Vida y formación de Juan Montero}

Como sucede con frecuencia, la actividad artística de Juan Montero estuvo determinada en parte por su formación personal. Juan Montero nació en la ciudad de México, fue hijo de Sebastián Montero de Espinosa y de Catalina Martínez y hermano de María y Sebastiana Montero. Su padre murió y su madre volvió a contraer nupcias con Antonio Maldonado, uno de los maestros ensambladores más importantes del siglo xvi. De este segundo matrimonio de doña Catalina nacieron Pedro Maldonado, alférez y maestro ensamblador, y fray Francisco Maldonado, fraile profeso del convento de San Diego de México. ${ }^{1}$

En fecha que aún desconocemos, Juan Montero se casó con Teresa de Aguilera, hija del arquitecto y aparejador mayor de la Catedral de México Rodrigo Díaz de Aguilera. Con ella tuvo “... .entre otros hijos

1 Efraín Castro Morales, "Juan Montero, ensamblador y arquitecto novohispano del siglo xvin", en Boletin 6 Monumentos Coloniales, Instituto Nacional de Antropologia e Historia, 6 (México, 1981), p. 7-8. Apud: AN (Notario Bernabé Sarmiento de Vera, años 1692-1695, s/f), AN (Notario Francisco de Olalde, años 1646-1648, fol. 423) y AN (Notario Martin del Rio, año 1685, fol. 490 vto). 
que ya son difuntos..." a fray Marcos Montero de Aguilera, quien en 1695 era religioso corista de la orden de Predicadores, y a María Montero de Aguilera, quien por aquel entonces tenía ocho años de edad. ${ }^{2} \mathrm{Su}$ esposa murió el 27 de febrero de $1693,^{3}$ de manera que en su testamento, dispuesto el 5 de enero de 1695, Juan Montero nombró por albacea, tutor y curador de la persona y bienes de su hija María, al bachiller Antonio de Quiñones. ${ }^{4}$

Su muerte sobrevino el 5 de febrero de 1695 , fue velado en el Sagrario Metropolitano y enterrado en la Catedral, 5 donde se le construyó una tumba. ${ }^{6}$

De esta manera vemos que la vida de Juan Montero transcurrió en medio del círculo de artistas coloniales del momento y es probable, como afirma Efraín Castro, que por haber sido educado por Antonio Maldonado, de él aprendiera el oficio de ensamblador, del mismo modo que su parentesco político con Rodrigo Díaz de Aguilera le haya proporcionado su formación de arquitecto, ${ }^{7}$ porque Juan Montero fue maestro examinado de escultura y de "... las artes de ensamblador, alarife, cantería y arquitectura..." 8 No obstante, es evidente que nuestro artista tuvo facilidad innata para practicar estos oficios artísticos, pues no sólo lo hizo al mismo tiempo, sino también con gran éxito.

\section{Ensamblador y escultor}

Pocas, pero muy importantes son las noticias que se tienen sobre la actividad que Juan Montero llevó a cabo como ensamblador, y todas

2 Ibidem. Apud: AN (Notario Bernabé Sarmiento de Vera, 5 de enexo de 1695, $\mathrm{s} / \mathrm{f})$. Martha Fernández, Arquitectura y gobierno virreinal: Los maestros mayores de la ciudad de México. Siglo XVII, presentación de Jorge Alberto Manrique, México, Instituto de Investigaciones Estéticas, Universidad Nacional Autónoma de México, en prensa, documentos número XV y XVI. Apud: AGN (Bienes Nacionales: 381, doc. 18). Dato del ME

3 Martha Fernández, op. cit, documento número VIII Apud: ASM (Libro de difuntos españoles, años 1693-1698, fol 14 r.).

4 Eiraín Castro Morales, op cit., p. 9-11. Apud: AN (Notario Bernabé Sarmiento de Vera, 5 de enero de 1695 , s/f). Martha Fernández, op. cit, documento número $\mathrm{XV}$. Apud: AGN (Bienes Nacionales: 381 , doc. 18) . Dato del IIE

5 Efraín Castro Morales, op. cit., p. 11. Apud: ASM (Libro de entierros españoles, núm. 4, años 1693-1698, fol. 103 vto). Martha Fernández, op. cit., documento número VIII. Apud: ASM (Libro de difuntos españoles, años 1693-1698, fol. 103 vto.).

6 Martha Fernández, op cit Apud: AGN (Bienes Nacionales: 381, doc. 18) . Dato del IIE.

7 Efraín Castro Morales, op. cit., p. 9, 17.

8 Martha Fernández, op cit. Apud: AGI (Audiencia de México: 2708), 
se deben al artículo de Efraín Castro "Juan Montero, ensamblador y arquitecto novohispano del siglo XviI". ${ }^{9}$

$\mathrm{El}$ oficio de ensamblador parece ser que fue el primero que practicó, pues la primera noticia en que se cita como maestro de tal arte se remonta al año de 1666. En vista de que los contratos conocidos ya se han publicado, no nos detendremos en ellos, sólo ratificaremos que de la información conocida hasta ahora, podemos ya hacer resaltar dos retablos importantes, ambos para la Compañía de Jesús: uno para la iglesia del Colegio de San Pedro y San Pablo de la ciudad de México, que fue contratado el 8 de marzo de 1678 , y el retablo mayor del templo de San Francisco Javier de Tepotzotlán, que ya había concluido el 4 de octubre de 1682.10

Por desgracia, no se conserva ninguno de sus retablos, pero a juzgar por las descripciones que publica el doctor Castro, Juan Montero se manifiesta como un artista barroco, amante de emplear la columna salomónica, por lo menos desde el año de 1676.

Respecto a sus esculturas, ya fueran de bulto o en relieve, no existe ninguna noticia documental hasta el momento, pero precisamente hablando de carencias, hemos de hacer notar que en ninguno de los contratos publicados por Castro se mencionan a los escultores encargados de realizar las tallas, como sí se hace en el caso de los pintores y doradores, lo que nos inclina a pensar que dado su título de maestro escultor, Juan Montero no sólo levantaría los retablos, sino que también se encargaría de los relieves y esculturas exentas. Del mismo modo es probable que algunas de las obras escultóricas -exentas y en relieve-, que aparecen en su inventario de bienes, hayan sido de su propia mano.

\section{Arquitecto}

Las noticias documentales han sido más generosas en relación al trabajo que desarrolló Juan Montero como arquitecto, lo que nos permite

9 Efrain Castro Morales, op. cit, p. 11-17. Apud: AN (Notario José de Anaya, año de 1674, fol 345 vto.), AN (Notario Andrés de Almoguera, año de 1681, fol. 1 y año de 1691, fol. 23). AN (Notario Fernando Veedor, año de 1675, fol. 9), AN (Notario Bernabé Sarmiento de Vera, años 1676-78, fol, 69), AN (Notario Marcos Pacheco de Figueroa, años 1679-78, fol. 7) y AN (Notario Martin del Rio, año de 1679, fol. 673).

10 Martha Fernández, op cit. Apud: AN (Notario Ignacio de Oviedo, 24 de octubre de 1682 , fol. 50 vto.) y AC (Arquitectura: 6) " Dato proporcionado por Elisa Vargas Lugo. Paleografía de Raquel Pineda. 
dividir la información en dos aspectos: los nombramientos que obtuvo el artista y las obras que realizó.

La historia de sus nombramientos es la siguiente: el 8 de mayo de 1678 el virrey fray Payo Enríquez de Rivera lo nombró aparejador mayor, veedor, solicitador y asentador de la obra de la Catedral de México en sustitución de su suegro, Rodrigo Díaz de Aguilera, que había fallecido el 30 de abril de ese mismo año. 11

Fue además maestro mayor del Santo Tribunal de la Inquisición hasta el año de su muerte. ${ }^{12}$ Según los autores del libro Palacio Nacional, este nombramiento se otorgó a Montero en $1680 .{ }^{13}$

El 7 de diciembre de 1682 el artista solicitó al virrey:

...le haga por Su Majestad honra y merced y favor de promoverle a la plaza de maestro mayor [de la catedral de México] ... en la futura y fallecimiento o por justo y legítimo impedimento del maestro mayor Luis Gómez de Trasmonte que actualmente lo está ejerciendo, en atención a ser la plaza de aparejador mayor que obtiene este otorgante, inmediata y consecutiva de ascenso a la de maestro mayor de dicha real fábrica... pidiendo en dicha merced, se revoque otra cualquiera que antecedentemente se haya fecho en dicha plaza de maestro mayor. ${ }^{14}$

El nombramiento que quería Montero se revocara era el de Cristóbal de Medina Vargas Machuca, quien lo había obtenido de manera interina el 3 de junio de 1679 por parte del virrey, recibiendo la confirmación real el 13 de mayo de $1680 .^{15}$

Pese a este interinato, parece ser que Juan Montero fue quien realmente sustituyó a Luis Gómez de Trasmonte durante sus ausencias y enfermedades, de tal manera que nuestro artista no se dio por vencido y a pesar de lo imposible que resultara revocar una confirmación real, siguió luchando por la maestría mayor de la Catedral de México. Así,

11 Ibidem. Apud, ASM (Libro de difuntos españoles, años 1671-1680, fol. 251 vto.) y AGI (Audiencia de México: 2708).

12 Francisco de 1a Maza, El Palacio de la Inquisición (Escuela Nacional de Medicina), México, Instituto de Investigaciones Estéticas, Universidad Nacional Autónoma de México, 1951 (Ediciones del IV Centenaxio de la Universidad de México, IX), p. 24. Martha Fernández, op. cit.. Apud: AGN (Bienes Nacionales: 381, doc. 18). Dato del IIE.

13 Palacio Nacional, México, Secretaría de Obras Públicas, Unidad Editorial, 1976, p. 300 .

14 Martha Fernández, op. cit. Apud: AGI (Audiencia de México: 2708).

15 AGI (Audiencia de México: 163, ramo 2, doc. 28). Martha Fernández, op. cit. Apud: AGI (Audiencia de México: 560) y AGI (Audiencia de México: 1100, lib. 36, fol. 398 vto. -400 vto.). 
del 7 al 11 de septiembre de 1684 preparó una información testimonial de su trabajo desarrollado en el templo, encaminado a alcanzar su objetivo.

Este documento ha sido parcialmente publicado por Efraín Castro, ${ }^{16}$ de suerte que no nos detendremos en él. Baste confirmar que los esfuerzos de Montero fueron vanos, pues precisamente el 11 de septiembre de 1684 Cristóbal de Medina hizo valer su interinato. Luis Gómez de Trasmonte ya estaba muy enfermo para entonces y no podía asistir a dirigir la obra de la Catedral, así que el día citado "dio principio a usar de el oficio que contiene el dicho maestro mayor Cristóbal de Medina por ausencia y enfermedad del dicho maestro mayor Luis Gómez de Trasmonte..." 17

Gómez de Trasmonte murió el 28 de septiembre de ese mismo año, ${ }^{18}$ y para el 3 de octubre el virrey conde De Paredes nombró a Cristóbal de Medina propietario en la plaza de maestro mayor de la Catedral de México. ${ }^{19}$ La confirmación real fue emitida dos años más tarde, el 21 de junio de $1686 .{ }^{20}$ En vista de tales circunstancias, Juan Montero dio por terminada su lucha.

El último nombramiento de que se tiene noticia, otorgado a Montero, nos lo proporcionan los autores del libro Palacio Nacional y se refiere a que el 3 de septiembre de 1694 el artista fue llamado para "regentear" la obra del Palacio Real en sustitución de Diego Rodríguez, disfrutando de un salario de trescientos pesos anuales. ${ }^{21}$

16 Efrain Castro Morales, op. cit., p. 23-26. Apud: Documento procedente de un archivo particular.

17 AGI (Audiencia de México: 163, ramo 2, doc. 28) .

18 Martha Fernández, op. cit., documento número VI. Apud: ASM (Libro de difuntos españoles, años 1681-1686, fol. 213 vto.)

19 AGI (Audiencia de México: 163, ramo 2, doc, 28). Heinrich Berlin: "Artífices de la catedral de México (investigación en el Archivo General de la Nación)" en Anales del Instituto de Investigaciones Estéticas, III, 11, (México, 1944), p. 31-32. Apud: AGN (Duplicado de Reales Cédulas: 28, fol. 234). Efraín Castro Morales. "Los maestros mayores de la catedral de México" en Artes de México, 182-183, año Xxi (México, 1976), p. 142. Palacio Nacional, p. 300. Efraín Castro Morales, "Juan Montero, ensamblador y arquitecto novohispano del siglo xvir", p. 26.

20 AGI (Audiencia de México: 163, ramo 2, doc. 28). Martha Fernández, op. cit. Apud: AGI (Audiencia de México: 560) y AGI (Audiencia de México: 1101, lib 39, tol. 150 vto-151 vto.). Martha Fernández, "Cristóbal de Medina Vargas y el acueducto de Santa $\mathrm{Fe}^{\prime}$ en Estudios sobre arte novohispano. Homenaje a Elisa Vargas Lugo, México, Instituto de Investigaciones Estéticas, UNAM, Apud: AGI (Audiencia de México: 560) y AGI (Audiencia de México: 1100, lib. 39, fol. 150 vto. - 151 vto.). 21 Palacio Nacional, p. 81. Apud: AGN (Archivo Histórico de Hacienda: 268-57). 
Con esto vemos que la formación de Juan Montero como arquitecto debió ser muy sólida y el prestigio que alcanzó, importante; aunque nunca haya llegado a la maestría mayor de la Catedral Metropolitana, obtuvo la del Santo Tribunal de la Inquisición, la cual aunada a su trabajo como aparejador mayor de la mencionada catedral y el cargo en el Palacio Real, le debieron garantizar la aceptación de su estilo artístico, un estilo que desarrolló precisamente en la época de transición entre el manierismo más ortodoxo de Luis Gómez de Trasmonte y Rodrigo Díaz de Aguilera y el barroco de fin del siglo xvir en la Nueva España.

El testimonio de esa aceptación lo encontramos en las muchas noticias documentales que concretizan su actividad como arquitecto en diversas obras de la ciudad de México. A partir de 1679 comienzan los datos de su participación en la construcción de casas, avalúos y reparaciones en conventos como los de La Concepción, Regina, San Bernardo y San Lorenzo. Amén de su trabajo en las obras públicas como el desagüe y los monumentos en los que tenía un nombramiento específico. ${ }^{22}$

Desgraciadamente, no queda en pie ninguna de las obras llevadas a cabo por Montero, con una excepción: las de la Catedral de México.

Como hemos dicho, en 1678 Juan Montero fue nombrado aparejador mayor de la catedral, cargo con el que murió el 5 de febrero de 1695. Esos diecisiete años los podemos dividir en tres periodos: de 1678 a 1682; de 1682 a 1684, y de 1684 a 1695 . La historia es la siguiente.

De 1678 a 1684 el maestro mayor de la catedral fue Luis Gómez de Trasmonte, pero simultáneamente desde 1679 se nombró un maestro mayor interino que fue Cristóbal de Medina "De esta suerte, de 1679 a 1684 en teoría existieron dos maestros mayores y un aparejador en la

22 Ibidem, p. 300. Glorinela González Franco, Ana Eugenia Reyes y Cabañas y Angelina Olivas Vargas, "Notas para una guía de artistas y artesanos de la Nueva España I" en Boletín 1. Monumentos Históricos, Instituto Nacional de Antropología e Historia, 1 (México, 1979) , p. 69. Glorinela González Franco, Angelina Olivas Vargas, María del Canmen Olvera Calvo y Ana Eugenia Reyes y Cabañas: "Notas para una guía de artistas y artesanos de la Nueva España II", en Boletin 4 Monumentos Histó. ricos. Instituto Nacional de Antropología e Historia, 4 (México, 1980), p. $92-93$. Glorinela González Franco, María del Carmen Olvera Calvo y Ana Eugenia Reyes y Cabañas: "Notas para una guía de antistas y artesanos de la Nueva España III", en Boletin 5 Monumentos Históricos, Instituto Nacional de Antropologia e Historia, 5 (México, 1981) , p. 80. Efraín Castro Morales, "Juan Montero, ensamblador y arquitecto novohispano del siglo xvi", p. 18-19. Martha Fernández, Arquitectura y gobierno virreinal, documento número XXX. Todos los autores se basan en documentos procedentes de diversos archivos mexicanos y extranjeros. El listado es muy extenso por lo que remito al lector a los estudios citados. 
construcción de la catedral; sin embargo, como hemos visto, Cristóbal de Medina no hizo valer su interinato sino hasta el 11 de septiembre de 1684, a sólo unos cuantos días de la muerte de Luis Gómez de Trasmonte, para que el 3 de octubre del mismo año se le concediera la titularidad. Por lo tanto, de este hecho inferimos que de 1678 a 1684 Juan Montero debió ser el verdadero sustituto de Gómez de Trasmonte.

Ahora bien, en una declaración notarial del año de 1682 se afirma que Luis Gómez de Trasmonte se encontraba totalmente "impedido", ${ }^{23}$ información que se ve reforzada por una circunstancia más: a partir de ese año se percibe un decaimiento total de su actividad, al grado de que es posible pensar que ya no asistiera a la obra de la catedral. Si a esto añadimos la noticia citada de que Cristóbal de Medina ejerció su interinato hasta 1684, tenemos que aceptar que de 1682 a 1684 el responsable de las obras fue Juan Montero.

En resumen, las noticias nos dicen que de 1678 a 1682 Juan Montero se mantuvo bajo las órdenes de Luis Gómez de Trasmonte; de 1682 a 1684, aparentemente dirigió la obra solo, y de 1684 a 1695 se tuvo que supeditar a Cristóbal de Medina.

$\mathrm{La}$ información que tenemos acerca de su obra concreta es escasa, pero importante. La primera se encuentra contenida en su Información testimonial del año de 1684. De acuerdo a la versión publicada por Efraín Castro, los testigos que aparecen en el documento coinciden en que Juan Montero “....intervino en la prosecusión [sic] de la puerta principál de enmedio desde la segunda cornisa hasta el tablero del escudo de las armas reales..." y que levantó las portadas procesionales "... cogiéndolas o formándolas desde su principio y se van continuando..." 24

La segunda noticia se refiere al hecho de que el 5 de marzo de 1693 llevó a cabo un reconocimiento de la catedral y sus oficinas. $Y$, finalmente, sabemos que el 14 de mayo del mismo año de 1693, al lado de Cristóbal de Medina, Diego Rodríguez y Juan de Cepeda

...exhibió y manifestó las plantas de perspectiva del adorno, arcos y capillas, bóvedas y ventanaje de la catedral de México de la parte de adentro y asimismo, la planta y dibujo de la fábrica que se ha de hacer para el Sagrario con todas las oficinas necesarias, habitación de

23 Martha Fernández, Arquitectura y gobierno virreinal. Apud: AGI (Audiencia de México: 163, xamo 2, doc. 28).

24 Efraín Castro Morales, "Juan Montero, ensamblador y arquitecto novohispano del siglo xvir", p. 23-26. Apud: Documento procedente de un archivo particular. 
los curas con lo que falta por ejecutar hasta quedar ejecutada perfectamente dicha obra. ${ }^{25}$

Los proyectos de 1693 nunca se llevaron a cabo, de manera que lo único que se conserva de la obra de Juan Montero es lo que declaró en su Información testimonial: las portadas del imafronte de la Catedral Metropolitana.

Los problemas que he encontrado acerca de la construcción de estas portadas (su secuencia cronológica, sus autores y el número de cuerpos que debieron haber alcanzado) los he analizado en un artículo titulado "Algunas reflexiones en torno a las portadas de la Catedral de México", ${ }^{26}$ de suerte que en este artículo solamente me concretaré a enumerar la obra que creo más factible se puede atribuir a Juan Montero.

En vista de que, por un lado en su Información testimonial los testigos le conceden el crédito absoluto de las obras que declaran, y, por otro, que su actuación en catedral como único responsable debió concretarse a dos años solamente (1682-1684), me parece que Juan Montero inició la construcción del tercer cuerpo de la portada del Perdón y es posible que haya levantado el primer cuerpo de las portadas procesionales.

El tercer cuerpo de la portada del Perdón nunca se terminó y, en vista de los datos conocidos, parece lógico pensar que en el siglo xviII se convirtiera en el remate que Manuel Tolsá derribó para levantar el que vemos actualmente; no obstante sabemos cómo pretendía Montero que fuera tal cuerpo. En su Información testimonial, el arquitecto José Durán declaró que don Juan "... siguió la forma antigua de la portada de enmedio...", ${ }^{27}$ lo que significa que Montero respetó el estilo de los cuexpos construidos, es decir, el manierista, ya considerado "antiguo" para 1684.

El primer cuerpo de las portadas procesionales lo conservamos: es también manierista y responde a la estructura de la portada del Perdón, por lo tanto sus características estarían más acordes con la época de Luis Gómez de Trasmonte.

Con esto llegamos a la conclusión de que en la Catedral de México

25 Martha Fernández, Arquitectura y gobierno virreinal. Apud: AGI (Audiencia de México: 810 , fol. 8 vto. - 16 vto; fol 18 r. -29 r).

26 Martha Fernández, "Algunas reflexiones en torno a las portadas de la Catedral de México" en Anales del Instituto de Investigaciones Estéticas, 53 (México, 1983), p. 81-94.

27 Efraín Castro Morales, "Juan Montero, ensamblador y arquitecto novohispano del siglo xvin", p. 25. Apud: Documento procedente de un archivo particular. 
Juan Montero se presenta como un artista que por encima de su gusto por eil arte barroco manifiesto en las descripciones que conocemos de sus retablos, respetó la estructura dada del monumento.

\section{Los ingresos de Juan Montero}

Dos documentos previos al inventario que aquí nos ocupa proporcionan información que debe tenerse en cuenta. Se trata de su Testamento, dispuesto el 5 de enero de $1695^{28}$ y un Codicitio redactado el 22 de enero del mismo año. ${ }^{29}$ Tales textos arrojan los siguientes datos en relación a sus finanzas.

Primero: no poseía casas, sino que alquilaba en cien pesos anuales una para vivir, casa que pettenecía a la Gatedral de México. Gracias a su partida de muerte ${ }^{30}$ sabemos que dicha casa estaba ubicada en la calle del Relox.

Segundo: tuvo varios esclavos. Uno de ellos, “... un mulato nombrado Antonio de San José..." a quien compró por cantidad de cien pesos en fecha no determinada. Asimismo, el año de 1693 su medio hermano, Pedro Maldonado, le extendió escritura de traspaso de " ... ciertas piezas de esclavos..." No se especifica el número exacto de "piezas", pero se infiere que fue más de un esclavo.

Tercero: en vista de que su hijo fray Marcos tuvo que renunciar a su herencia para poder profesar, pidió a su padre que de su parte mantuviera en su casa a dos niñas, ellas fueron Inés Tomasa Montero y Juana Rosa Montero, quienes en 1695 tenían doce y siete años respectivamente y a las cuales, aclaró don Juan, "... he criado al patejo de mis hijos legítimos..."

Cuarto: nombró por heredera universal de sus bienes a su hija María Montero de Aguilera, de ocho años de edad, aunque él mismo solicitó que de sus bienes se dieran dos pesos a cada una de "... las mandas forzosas y acostumbradas..."; dos pesos para "... los Santos Lugares de Jerusalén..."; dos pesos "... para ayudar a la beatificación del Venerable Gregorio López... ” y, además, pidió que se extrajeran cuatrocientos pesos para socorrer las necesidades y estudios de su hijo fray

28 Martha Fernández, Arquitectura y gobierno virreinal, documento número XV. Apud: AGN (Bienes Nacionales: 381, doc. 18). Dato del IIE.

29 Ibidem, documento número XVI Apud: AGN (Bienes Nacionales: 381, doc 18). Dato del IIE.

30 Ibidem, documento número VIII. Apud: ASM (Libro de difuntos españoles, años 1693-1698, fol. 103 vto). 
Marcos y trescientos pesos de oro común y algún ajuar extraído de lo mejor de sus bienes para el matrimonio de las dos niñas expuestas en su casa.

Quinto: reconoció sólo dos deudas: una de sesenta pesos de oro común al mercader Lucas de Mesa, y la otra de once pesos y dos tomines al maestro de confitero Pablo Suárez.

Sexto: concretamente en su Codicilio declaró que era pobre.

El hecho de que hubiera tenido esclavos y de que de la herencia de su hijo hubiera sostenido dos niñas, es buen indicativo de que la situación económica de Juan Montero era por lo menos estable; pero analicemos las fuentes de ingreso con las que el artista contó para solventar sus propios gastos, los de sus hijos, los de las huérfanas, la renta de la casa y la alimentación de sus esclavos.

De la documentación conocida hasta ahora se desprende que Montero contó en principio con dos fuentes de ingresos: por un lado, los salarios fijos que recibía anualmente por los nombramientos que había obtenido $y$, por otro, el pago de sus obras.

Respecto a sus nombramientos, recordemos que fue aparejador mayor de la catedral, maestro mayor del Santo Tribunal de la Inquisición y que en 1694 fue llamado para "regentear" la obra del Palacio Real.

Cuando fue nombrado aparejador mayor de la catedral el año de 1678, el sueldo que se le asignó fue de quinientos pesos anuales. El año de 1690 se emitió una real cédula fechada el 9 de agosto en la que se argumentó que en vista de que ya se había emparejado la altura de la iglesia y se habian levantado el crucero y el cimborrio "... parecía no haber tanto trabajo..." y, por lo tanto, se dispuso que se rebajase el sueldo del aparejador a trescientos pesos anuales. ${ }^{31}$ La cédula, sin embargo, no se cumplió y de ello da fe Juan Montero en una declaración de su testamento en la que afirmó que por ejercer el cargo de aparejador tenía asignado "... salario de doce reales en cada un día...", lo que venía a ser un total de poco más de quinientos pesos anuales.

Como "regente" de las obras del Palacio Real se le asignó un sueldo de trescientos pesos anuales, dinero que no pudo recibir completo, pues su nombramiento data del mes de septiembre de 1694, y su muerte sobrevino el 5 de febrero del año siguiente, de tal manera que si algo se le pagó, debió ser poco más de cien pesos.

Desconocemos el salario que la Inquisición pagaba a sus maestros mayores, es de suponerse que debió ser menor al que asignaba la cate-

31 Ibidem. Apud: AGI (Audiencia de México: 1075, lib. 33, fol $144 \mathrm{r}$ - 145 vto). 
dral, que fluctuó entre los quinientos y ochocientos pesos en el siglo xvII, pero equiparable quizás al de sus aparejadores mayores.

Así tenemos que la cantidad fija y segura que Montero recibió anualmente debió andar alrededor de los mil pesos, suma nada despreciable en aquella época.

Pero esas no fueron las únicas ganancias que Juan Montero obtuvo por su trabajo, también cobró por las obras que llevó a cabo por cuenta propia. En el caso de los retablos es difícil determinar el porcentaje que él llevaría del costo total que tuvieron. Como autor del proyecto y director de cada uno es de suponerse que sacaría la mayor parte, de tal manera que enumeraremos los datos publicados en este sentido por Efraín Castro, para darnos una idea aproximada de lo que don Juan podría haber cobrado. 32

E1 7 de eneno de 1676 contrató un retablo de tres cuerpos para la iglesia del convento de Nuestra Señora de los Ángeles de Churubusco, su costo fue de tres mil trescientos pesos. El 8 de marzo de 1678 contrató el retablo que citamos en otro apartado para el Colegio de San Pedro y San Pablo, su costo sería de cuatro mil quinientos pesos. El 8 de agosto de 1679 contrató el retablo mayor de la iglesia del Convento de Santa Isabel de la ciudad de México, por el cual recibiría Montero tres mil ochenta pesos. Según Efraín Castro, en 1681 Juan Montero contrató el retablo mayor del templo de San Francisco Javier de Tepotzotlán, 33 por el cual se le pagaron en octubre de 1682 cuatro mil quinientos pesos. 34

En relación a los honorarios que recibió por algunas de sus obras de arquitectura, tenemos los siguientes datos.

En fecha que desconocemos reparó una celda en el convento de Regina Coeli, obra que importó la cantidad de treinta pesos. En 1680 tenía a su cargo la construcción de una casa para Juan de Sosa, cuyo valor era de setenta y dos pesos. Del 29 de enero al 27 de agosto de 1689 reparó unas casas pertenecientes al Convento de La Concepción ubicadas en la plaza de San Juan de la Penitencia, reparaciones que

32 Efraín Castro Morales, "Juan Montero, ensamblador y arquitecto novohispano del siglo xvir", p. 11-17. Apud: AN (Notario Fernando Veedor, año de 1675, fol. 9). AN (Notario Marcos Pacheco de Figueroa, año de 1673, fol 7) y AN (Notario Martin del Rio, año de 1679, fol. 673).

33 Efraín Castro Morales, "El patronato de 'Tepotzotlán", conferencia dictada el 12 de agosto de 1982 en el Museo Nacional de Antropología e Historia de Méxiso.

34 Martha Fernández, Arquitectura y gobierno virreinal. Apud: AN (Notario Igna. cio de Oviedo, 24 de octubre de 1682, fol. 50 vto) y AC (Arquitectura: 6). Dato proporcionado por Elisa Vargas Lugo. Paleografía de Raquel Pineda. 
montaron la cantidad de dos mil ciento siete pesos, un tomín y medio, según la memoria de gastos que presentó el 31 de agosto. El 4 de marzo de 1689 había comenzado la construcción de dos casas con dos accesorias para el Convento de Regina, valuadas por Cristóbal de Medina y Juan de Cepeda en siete mil quinientos pesos. Del primero de diciembre de 1693 a febrero de 1695 se hizo cargo de las reparaciones de unas casas en la calle de Jesús María, propiedad del Convento de Regina; el costo de las obras se había calculado en dos mil cien pesos. ${ }^{3 \check{5}}$ Todo esto sin contar lo que recibiría por otros trabajos, como por ejemplo, los avalúos, cuyo pago no se estipula en los documentos correspondientes.

De los datos citados lo lógico sería concluir que gracias a su versatilidad artística Juan Montero debió gozar de una buena posición económica a lo largo de su vida y, a menos que no capitalizara sus ganancias podríamos creer en la pobreza que declaró en su Codicilio. Veamos, pues, lo que en este sentido nos revela su Inventario de bienes.

\section{El inventario de bienes}

El inventario fue realizado a petición del propio Juan Montero para que de sus resultados su albacea

... proceda a la venta y almoneda de ellos por excusar gastos y que se consuma el poco valor de dichos bienes en semejantes diligencias por declarar, como declara, estar hechos dichos avalúos y aprecios a su satisfacción sin perjuicio y daño alguno en que proceda dicho albacea sin que por ello se le haga cargo ni pida cuenta porque de todo le releva y de fianza por la mucha satisfacción y confianza que tiene de la cristiandad del susodicho.

Su albacea, Antonio de Quiñones, presentó la solicitud para llevar a cabo el inventario el 3 de febrero de 1695 ante el licenciado Antonio Zezati, abogado de la Real Audiencia y teniente de corregidor de la ciudad de México, quien autorizó se llevara a efecto. Así, del 12 al 18 de febrero del mismo año se realizó el inventario. Los encargados de la tasación de los bienes fueron: Antonio de Arellano, pintor; Pedro de

35 Ibidem, documentos número XV y XXX Apud: AGN (Bienes Nacionales: 381, doc. 18), dato del IIE; AGN (Bienes Nacionales: 100, doc. 58), dato de Glorinela González Franco, Ana Eugenia Reyes y Cabañas y Angelina Olivas Vargas en "Notas para una guía de artistas y artesanos de la Nueva España I", p" 69; AGN (Bienes Nacionales: 188, doc. s/n) y AN (Notario José Almogueras, año de 1680 , fol. 10 vto.), dato del IIE. 
la Torre, carpintero; Gregorio Pardo, platero y Pedro de los Reyes, sastre; ${ }^{36} \mathrm{y}$, finalmente, el 15 de febrero fue citado también Manuel de Peralta, " . . persona inteligente en todas materias, tasador nombrado por las partes para la tasación de las casas y menudencias que restan por inventariar..." ${ }^{37}$ De acuerdo a lo que aparece en el documento, los maestros calcularon en bienes un total de mil seiscientos ochenta y tres pesos, cinco tomines y seis granos.

De los objetos incluidos en el inventario cabe hacer mención de los siguientes: veinticinco lienzos de pinturas con diferentes temas, entre ellos una serie de tres cuadros "... de más de dos varas de alto..." con la representación de la Pasión de Cristo; doce tablas entre las que destacan cuatro con los Apóstoles, "cuatro tableros de a tres cuartas de alto de Santa Lucía..." y "dos tableros de vara con dos ángeles..."; seis láminas, dos de las cuales representaban Sibilas; y “... una lámina de Mechoacán de pluma con un marco de tapincerán de media vara de grueso...", que se ha de referir con toda seguridad a un mosaico de plumas. Pieza digna de especial atención es un biombo de diez hojas "... de la coronación de Carlos Quinto..."

Asimismo, se mencionan seis esculturas, entre ellas una de Nuestra Señora de la Concepción; once relicarios: seis parecen ser de madera y cinco son piezas de joyería; veintinueve espejos, seis escritorios, cinco bufetes, "una pileta para agua bendita" y una puerta de Sagrario "media talla con la Resurrección del Señor, dorada..."; además de varios objetos propios del mobiliario de una casa, como dos camas, una mesa, ocho sillas, dos bancas, un baúl y varias alhajas. De estas últimas se artoja digna de aprecio "...una corona de plata sobredorada con sobrepuestos de piedra que sirve a la Virgen..." Entre sus pertenencias de uso personal se encontraba la biblioteca, constituida por veinte libros de historias y tratados, y sus herramientas de trabajo.

La cantidad alcanzada por algunos objetos del inventario es extraña, ¿quién en su casa llegaría a reunir veintinueve espejos, once relicarios, seis escritorios y cinco bufetes?, e implementos tan singulares como una puerta de sagrario y una "pileta para agua bendita". Esta circunstancia hace pensar que la mayoría de los objetos citados no pertenecían a la casa-habitación de Juan Montero, sino a una tienda: su tienda.

No obstante, esto no es lo único sorprendente del inventario: cuando 
se cita a Manuel de Peralta, se aclara que tasaría "casas", mismas que no aparecen en el inventario ni menciona Montero en su testamento.

Pero el hecho más extraño es que el albacea de Juan Montero, Antonio de Quiñones, declaró que no había podido rematar los bienes en las almonedas que había realizado "... por estar subidos los avalúos...", y entonces solicitó “... nueva licencia y facultad para poderlos rematar fuera de almoneda en las personas y por los precios que hallase, de que protestaba presentar relación jurada..." La licencia le fue concedida el 3 de marzo de $1695,{ }^{38}$ o sea a sólo catorce días de haber terminado los avalúos, por lo cual da la impresión de que existía cierto apremio por rematar los bienes, aún más, la venta sólo alcanzó la cantidad de mil doscientos setenta y cinco pesos, dos tomines y seis granos, que implica pérdida respecto a lo tasado por los maestros.

Es posible que el siguiente dato, tampoco mencionado en el testamento de Montero, nos abra una luz respecto a los citados puntos oscuros del inventario de bienes: el 25 de noviembre de 1700 Antonio de Quiñones

...otorga poder a Gaspar de Toledo, vecino de México, para que en su nombre parezca en el Juzgado Eclesiástico del obispado de Puebla ante el señor juez provisor y vicario general subdelegado de $\mathrm{Su}$ Santidad y ante quien y con derecho pueda, deba y siga el artículo del pleito remitido en grado de apelación que en el Juzgado Eclesiástico de este arzobispado ha seguido el licenciado Manuel López de Loes, presbítero, contra bienes del maestro Juan Montero por cantidad de pesos de una fianza que hizo al licenciado Pedro Moreno, presbítero, difunto... ${ }^{39}$

y se pidió al otorgante exhibiese los bienes de Juan Montero.

Así descubrimos que pese a lo declarado en su testamento y codicilio, Juan Montero tuvo una deuda lo suficientemente importante como para

38 Ibidem. Apud: AGN (Bienes Nacionales: 381, doc. 18). Dato del IIE.

39 Ibidem. Apud: AN (Notario José Almogueras, 25 de noviembre de 1700 , fol. 208 vto. 209 r). Dato del IIE.

Abreviaturas de los archivos citados

AC: Archivo Cervantes. México, D. F,

AGI: Archivo General de Indias Sevilla, España,

AGN: Archivo General de la Nación. México, D. F。

AN: Archivo General de Notarias México, D. F.

ASM: Archivo del Sagrario Metropolitano México, D. F. 
que por ella se le abriera un juicio. Ignoro el resultado de esa gestión, lo único que parece claro es que Antonio de Quiñones no habrá podido exhibir los bienes de Montero porque - al menos los reconocidos en el inventario-, los había logrado salvar al haberlos vendido cinco años antes. Sin embargo, el documento nos permite plantear algunas hipótesis que creo pueden ayudar a clarificar las incógnitas que abre la información que he expuesto.

En primer lugar es factible suponer que al ocultar la deuda en su testamento y codicilio, Juan Montero mintiera acerca de sus bienes y en cambio declarara una pobreza que debió estar muy lejos de padecer.

Por lo tanto, me inclino a pensar que efectivamente el artista debió tener una tienda como el escultor y ensamblador que fue, al mismo tiempo que, en vista de que también fue arquitecto, las "casas" que según el inventario de bienes debió haber valuado Manuel de Peralta, realmente existieron.

Ahora bien, no tenemos datos concretos que nos ayuden a sustentar estas hipótesis, pero podemos acudir a un hecho de tipo general y a una circunstancia de tipo personal. El primero se refiere a que el objetivo que se persigue en un testamento es la protección económica de los herederos, por lo tanto; se les trata de librar de la mejor manera posible de deudas que pudieran acabar con los bienes legados.

La circunstancia de tipo personal es que Juan Montero tenía una bija de sólo ocho años de edad huérfana de madre, que en ese momento dejaba también huérfana de padre y sin más medios de vida que su propia herencia, de suerte que él y su albacea debieron procurar el rescate de la mayor cantidad de bienes que les fuera posible para salvaguardar de alguna manera el futuro de la pequeña María.

Hasta ahora y mientras no aparezcan nuevos datos documentales, es imposible confirmar nuestras hipótesis. No obstante, al exponerlas, queremos abrir un camino en el estudio del aprovechamiento económico que los artistas hacían de su trabajo y de la manera como parece que podian canalizar sus ganancias en el siglo xvir. Juan Montero de Espinosa no fue un caso único en este sentido, es sólo un ejemplo; otros artistas contemporáneos a él, como Cristóbal de Medina Vargas, también completaron sus ingresos con diversas fuentes, aparte de los sueldos. que les correspondieron por nombramientos, lo que muchas veces les permitió lograr un verdadero enriquecimiento. 


\section{DOCUMENTO}

Testamento y codicilio de Juan Montero, difunto, maestro que fue de arqui. tectura; inventario y aprecio de sus bienes, relación jurada y instrumento de su comprobación que presenta el Bachiller don Antonio de Quiñones Osorio, Presbítero, como su albacea, tenedor de bienes.

En cumplimiento del auto de uso, yo Diego Diaz de Rivera, escribano del Rey nuestro señor, público escribano práctico del número de esta ciudad de México, hice sacar y saqué un tanto relativo de los inventarios y aprecios que la petición refiere, cuyo tenor es como sigue

[Al margen]

\section{Testimonio}

A los diez de febrero del año pasado de mil y seiscientos y noventa y cinco, ante el Licenciado don Antonio Zezati, abogado de esta Real Audiencia y teniente de Corregidor de esta dicha ciudad por Su Majestad, pareció el Licenciado don Antonio Quiñones, Presbítero Domiciliario deste Arzobispado, y por petición que presentó Dijo que Juan Montero, por cláusula del testamento que otorgó, so cuya disposición talleció, y de un cobdicilio que presentó con el juramento necesario, le nombró por su albacea y tenedor de bienes insolidum y tutor de su menor hija, y que para que en todo tiempo constare los bienes que por fin y muerte quedaron del dicho Juan Montero, pidió licencia para hacerlos que se le concedieron, habiendo nombrado avaluadores para ello y con citación de Juan de Monzón, curador ad liten de María Montero, hija y heredera de dicho difunto, los cuales son del tenor siguiente

\section{[Al margen]}

\section{Inventario}

En la ciudad de México, a doce días del mes de febrero de mil y seiscientos y noventa y cinco años, estando en la casa que fue de la morada de Juan Montero, maestro de arquicectura, ante mi el escribano y testigos, el Bachiller don Antonio de Quiñones, Presbítero, su albacea y tenedor de bienes y presentes Juan de Monzón, curador ad liten de María Montero đe Aguilera, menor hija y heredera de dicho difunto, y Antonio de Arellano, pintor, Pedro de la Torre, carpintero, Gregorio Pardo, platero, y Pedro de los Reyes, sastre, a todos los cuales doy fe conozco, y dicho Bachiller, usando de dicha licencia, hizo el inventario de los bienes del susodicho, que fueron avaluados en la manera siguiente

Número 1 Primeramente, tres lienzos de la Pasión de Vendidos a 9 pe- Nuestro Señor Jesucristo de más de dos varas sos a Joseph de de alto, en bastidor, que tasa el dicho AntoFuentes 
2 Una imagen de Nuestra Señora de Guadalupe Al dicho en 7 pe de siete cuartas de alto con su marco negro $\operatorname{sos}$

ordinario, en nueve pesos

Número 3 Otro lienzo de Nuestra Señora de la Soledad Al dicho en 5 pe- de una vara con su marco negro, cantoneras sos doradas, en siete pesos

4 Otro del Nacimiento, de dos varas de largo y vara y tercia de alto, en bastidor, en ocho pesos

5 Otro de Santa Gertrudis de dos varas de alto en bastidor, en cinco pesos

6 Otro dicho de la Huida a Egipto de vara y cuarto de largo, en cuatro pesos

7 Otro de Nuestra Señora de Belén con su marco fingido de tapincerán en siete pesos

8 Un lienzo de Santa Teresa de Jesús de vara Al dicho en 5 pe. y tercia de alto con su marco dorado, en sos siete pesos

9 Otro de Nuestra Señora del Pópulo de dos tercias con su marco dorado, que tasa el dicho maestro en tres pesos

10 Cuatro tableros de a vara y tres cuartas de Vendidos a Tomás largo en que están los doce Apóstoles, de a de la Piña en 10 cuatro pesos cada tablero pesos

11 Un rostro, digo dos, de Santa Teresa y Nuestra Señora de las Rocas con sus marcos dorados, en siete pesos ambos

12 Dos tableros de a cuarta de Nuestra Señora de los Dolores y Cristo coronado de espinas, con sus marquitos dorados, a dos pesos

13 Cuatro láminas de bronce con sus marcos de tapincerán de a cuarta, apolillados, a doce reales cada una

Dos relicarios dorados con sus ángeles y seras de acnus, a tres pesos 
14 Un relicario de más de una cuarta con su vidriera de cristal y reliquias, con su guarnición de talla dorada, en diez pesos

15 Otro relicario dorado de dos tercias de alto de talla con sus colunitas, en tres pesos y medio

16 Dos relicarios ovados con sus marcos dorados y sus vidrieras y seras de acnus, de media vara poco más de alto, en seis pesos

17 Cuatro espejos con sus marcos dorados y lunas de a tercia con relumbrones en el marco, a tres pesos cada uno

18 Iten, un espejo con luna de a tercia y marco negro, en tres pesos

19 Dos láminas de las Sibilas con sus marcos dorados, de a tercia, a doce reales

20 Cuatro, digo seis pares de espejos con sus marquetos [sic] de a tercia, a seis reales

Número 21 Otros seis marquitos de espejos de relumbrón, a dos reales cada uno

22 Una Nuestra Señora de Betén de una vara de alto y cuadro fingido de tapincerán, en cinco pesos

23 Otros seis marquitos de relumbrones que tasa A María Jaziut en a peso cada uno 4. pesos

24 Dos lienzos de Santa Catarina Mártir y Santa A Antonio de Cas- Teresa, de a vara y cuarta de alto, a cinco tro en 6 pesos pesos

25. Un San Miguel Arcángel con su marco doxado de tres cuartas, en cuatro pesos

26 Una cinta de un Santo Cristo de tres cuartas de alto con su baldoquín de terciopelo, en cinco pesos

27 Cuatro tableros de a tres cuartas de alto de Santa Lucía a doce reales

28 Un lienzo del Señor San José con su marco negro, de vara y tercia de alto, en cinco pesos 
29 Un biombo de diez tablas de la coronación

Vendido en 40 pe- de Carlos Quinto, en cincuenta y cinco pesos $55 \mathrm{p}$. sos a Tomás de

Guevara

Número 30 Un rodastrado de lienzo pintado de diez Al dicho en 16 pe. tablas de fábulas, en veinte pesos

$20 \mathrm{p}$ sos

31 Un Niño Jesús de media vara de alto con su peana dorada y potencias de plata, en doce pesos

32 Un San Nicolás de Tolentino de dos tercias de alto con su peana dorada, en siete pesos

33 Otra peana del Señor San José de tres cuarA Nicolás Ximé- tas de alto, en doce pesos nez en 6 pesos

34 Otra del Señor San Miguel de una vara de Al dicho en 8 pe- alto, en catorce pesos $\operatorname{sos}$

35 Una imagen de Nuestra Señora de la ConAl dicho Nicolás cepción con su peana, estofada y dorada, en Ximénez en 20 treinta pesos pesos

36 Una hechura de un Santo Cristo de una cuarta en su peana y cruz de tronco, en tres pesos

37 Dos tableros de vara con dos ángeles, a veinte reales cada uno, cinco pesos

38 Un lienzo de Señor San Antonio de más de vara en bastidor ordinario, en un peso

39 Un lienzo de un Santo Crucifijo viejo, en ocho reales

40 Un lienzo de Nuestra Señora del Pópulo muy viejo, en doce reales

41 Dos cajas: una de nogal y otra de cedro de Vendidas a Juan La Habana, de vara y media con sus herraParedes en 18 pe- jes, que tasa el dicho Pedro de la Torre en sos treinta pesos ambas 
42 Un lienzo de San Anastasio de una vara con su marco de madera ordinario, en ocho reales

$1 \mathrm{p}$

43 Una Verónica de media vara en bastidor, en veinte reales

44 Una lámina de Mechoacán de pluma con un marco de tapincerán de media vara de grueso, en tres pesos

45 Una puerta de Sagrario, media talla con la Resurrección del Señor, dorada, en dos pesos

46 Veinte... [ilegible] tabla viejos, en dos pesos 2 p.

47 Otra caja de cedro de poco más de vara de La Habana con su llave y pies torneados en seis pesos

48 Otra dicha de... [ilegible] de vara y cuarta con su llave, en doce reales

49 Otra dicha de tapincerán de dos tercias embutida con su herraje, en tres pesos

Número 50 Un escriptorio de la Sierra de dos tercias de largo con su llave, en tres pesos

51 Otro de Mechoacán de media vara con su herraje, en dos pesos

52 Un bauleto de Oaxaca de media vara embutido con su herraje, en veinte reales

53 Otro escriptorio con sus gavetas de Guaxaca de dos tercias, en dos pesos

54 Otro dicho de Mechoacán de tres cuartas con siete gavetas, en dos pesos

55 Un bufetillo con sus pies torneados, sobrepuesto de tapincerán y cedro, en cuatro pesos

56 Un escriptorio de vara y cuarta de largo con Vendido a Juan su escribanía y remate embutido de hueso y de Paredes en 22 naranjo con sus llaves y pie torneado de pesos cedro, en treinta pesos 
57 Otro escriptorio de una vara de largo con Al dicho en 6 pe- dos contadorcillos embutidos de tapincerán $\operatorname{sos}$ con su pie de celosías de madera ordinaria, en ocho pesos

58 Una cama entera de Tepeguaxe bronceada, A Francisco Mar- en doce pesos chena en 8 pesos

Número 59 Otıa dicha de tapincerán entera llana, en cuatro pesos

60 Ocho sillas de vaqueta leonada, maltratadas, A Francisco Mar- a dos pesos chena a 12 reales cada una

61 Una mesa de cedro con su cajón y llave, de Al dicho en 3 pe- vara y media de largo, en cinco pesos sos

62 Una banca de nogal con sus clavos de bronAl dicho en 1 ce, en dos pesos peso

63 Un bufete de cedro blanco son sus pies torneados, en veinte reales

64 Otro bufete de vara y tercia de tabla de nogal y los pies de madera ordinaria, en veinte reales

65 Otro dicho de caoba de una vara de largo, que tasa dicho maestro en tres pesos

66 Un bufetillo de una vara de cedro blanco, en un peso

67 Un estante de libros de madera ordinaria, apolillado, de dos de alto, en dos pesos

68 Una banca de madera ordinaria, en cuatro reales

$\mathrm{Y}$ en ese estado se quedó dicho inventario, para lo proseguix y los bienes en él contenidos quedaron en poder del dicho Bachiller don Antonio de Quiñones, como tal albacea y tenedor de bienes de que se hizo cargo para dar cuenta, a que obligó sus bienes, y lo firmó con dicho curador y avaluadores, siendo testigos Manuel de Peralta, el Bachillex don Carlos de Salinas, presbítero, y Diego Díaz de Rivera, vecinos de México. Bachiller don Antonio de Quiñones Osorio. Juan de Monzón. Pedro de la Torre. Antonio de Arellano. Ante mi, Juan Díaz de Rivera, escribano real y público. 
[Al margen]

\section{Inventario}

En la ciudad de México, a catorce días del mes de febrero de mil seiscientos y noventa y cinco años, ante mí el escribano y testigos, el dicho Bachiller don Antonio de Quiñones, presbítero, albacea y tenedor de bienes del dicho Juan Montero, presente Juan de Monzón, curador ad liten de María Montero de Aguilera, menor hija y heredera de dicho difunto, y Gregorio Pardo, maestro de platero y Pedro de los Reyes de sastre, terceros apreciadores, a todos los cuales doy fe que conozco, prosiguiendo en los inventarios y aprecios de los bienes de dicho difunto, se hizo en la manera siguiente

Número 69 Primeramente, unos sarcillos... [ilegible] Vendidos a Nico- de calabacillas de perlas, que de declaró lás de Soto en 45 [sic] el dicho albacea estar empeñados en pesos y sólo son treinta pesos, por habérselo dicho así el dicho de $\mathrm{mi}$ cargo 15 difunto $y$ éstos se hallaban antecedentepesos, porque los mente por dicho maestro Gregorio Pardo en 30 pesos del em- cincuenta pesos, con que queda de valor peño pagué a Pe- de ellos en veinte pesos

$20 \mathrm{p}$ dro de la Parra como consta de un recibo que no pongo en data

70 Otros dichos de medias lunas con cuatro corAl dicho en 35 nerinas ${ }^{1}$ cada uno y calabacillas de perlas, pesos en cuarenta pesos

71 Otros dichos pequeños con tres pendientes Al dicho en 3 pe- de perlas, en cuatro pesos sos

72 Unas pulseras de medio rostrillo ${ }^{2}$ que pesaAl dicho a 28 pe- ron dos onzas y tres adarmes 3 largos, que sos la onza tasó a treinta y cinco pesos onza

1 Cornerinas. Real Academia Española: Diccionario de autoridades, 3 v., ed facsímil, Madrid, Editorial Gredos, 1963 (1a. ed. 1726): "Piedra preciosa semejante a la uña humana, con algún génexo de brillante y venas, como la del sardo o jaspe, imitando también su color."

2 Medio rostrillo Diccionario de autoridades: "Se llama... una especie de aljo far, no muy menudo, del cual entran quinientos granos en onza, y éste se llama rostrillo grueso; y si entran seiscientos, rostrillo cabal; el de setecientos, rostrillo menudo. Entrando ochocientos y cincuenta granos en onza, se llama medio rostrillo grueso. El de mil granos, medio rostrillo mejor; y si llegan a entrar mil doscientos granos, se llama medio rostrillo."

3 Adarme. Diccionario de autoridades: "La décima parte de una onza o la mitad de la drachma. Puede ser voz corrompida del griego Drachma, cuya mitad monta.", 
73 Una soguilla 4 de perlas de corales que avaAl dicho en 6 pe- lúa en siete pesos sos

Número 74 Otra dicha de perlas de corales más menudos, en cinco pesos

75 Unas pulseras pequeñas de perlas y corales, en seis pesos

76 Tres sortijas viejas de oro que pesan dos Al dicho en 4 pe- castellanos y seis tomines, en seis pesos sos

77 Un relicario de plata con su sera de acnus en dos pesos

78 Otio más pequeñito, en un peso $1 \mathrm{p}$.

79 Otro relicario de Nuestra Señora de la Soledad y Nuestro Señor de la Coluna, en cuatro pesos

80 Cinco clavos de plata con sus piedras, en dos pesos

81 Una cajita de filigrana para polvos que pesó dos onzas y una ochava, en quince reales

82 Una bandejita con sus guarniciones de oro, en cuatro pesos

83 Seis cucharitas de plata para dixes, en diez reales

84 Un ramito de coral con su casquillo de plata, en un peso

85 Una campanilla de plata con su pito, en dos pesos

86 Un relicario de Santa Gertrudis y Nuestra Señora de Guadalupe, en tres reales

Número 87 Un acnus de azabache de reliquias en doce reales

88 Un coquito 5 con otras piezas de plata, en tres pesos

4 Soguilla. Diccionario de autoridades: "Se llama... la trenza delgada que se hace con el pelo." En este caso parece referinse a un adorno para el pelo.

5 Cocos. Diccionario de autoridades: "Se llaman... unas cuentecillas que vienen de las Indias, de color obscuro, y con unos agujerillos, de que se hacen Rosarios y otras cosas." 
89 Siete cocos guarnecidos de plata que tasa A Nicolás de Soto a veinte reales cada uno en $1 \mathrm{p}$.

90 Un caracol con su pie de plata, en seis pesos

91 Una rociadera, de losa de china, guarnecida de filigrana, en tres pesos

92 Un salero de plata con su tapa que pesó tres marcos y onza y media, a siete pesos marco, monta

93 Otro dicho pequeño sin tapa, que pesó nueve onzas y cuarta, a siete pesos marco, hacen

94 Diez y seis cucharas de plata, una pileta para agua bendita, dos chapas de fuente, una cazuela y un collar de San Blas, todo de plata que pesó tres marcos cuatro onzas y una cuarta, a siete pesos el marco, monta

95 Una corona de plata sobredorada con sobrepuestos de piedras que sirve a la Virgen, que pesó marco y medio, que tasó en doce pesos

Número 96 Una gargantilla de perlas de medio rostrillo que pesó una cuarta, que tasa en ocho pesos

8 p.

97 Unos botones de plata y un llavero viejo que pesó marco y medio, a siete pesos marco

98 Un cuchillo con su cacha de carey viejo, en cuatro reales

Ropa

99 Una manteleria de chorreado 6 verde guarA María de To- necida con encajes blancos que tasa el dicho rres en 7 pesos Pedro de los Reyes, sastre, en doce pesos

6 Chorreado. Martín Alonso: Enciclopedia del ldioma. Diccionario histórico y moderno de la lengua española (siglos XII al XX), etimológico, tecnológico e hispanoamericano, $3 \mathrm{v}$, Aguilar, 1947: "Dícese de la res vacuna que tiene el pelo con rayas verticales, de color más obscuro que el general de la capa. Aplifase a cierta especie de raso." 
100 Un vestido de raso labrado de colores, polleA Nicolás de Soto ra y bombacha 7 guarnecidos de encajes en 40 pesos negros, en cincuenta y cinco pesos

101 Otro dicho, pollera y bombacha de tela flor $\mathrm{Al}$ susodicho en de romero, con encajes de seda cruda, en 60 pesos ochenta y cinco pesos

102 Unas naguas de raso de primavera con tres Al dicho en 8 pe- encajes de seda cruda, en diez y seis pesos sos, por estar maltratadas

103 Una bombacha de fondo negro con botones A María Rodri- de azabache, guarnecida de encajes, en caguez en 8 pesos torce pesos

104 Un capotillo de paño de grana, en doce A la dicha en 5 pesos pesos, estaba ya muy viejo

105 Una bombacha de raso encarnado con faldiA la dicha en 2 llas cortas guarnecidas de encajes blancos en pesos cuatro pesos

106 Otra bombacha de tela... [ilegible] con falA la dicha en 2 dillas cortas y encaje de oro falso, en seis pesos pesos

107 Otra dicha de felpa negra antigua en dos pesos

108 Otra dicha de raso negro antigua, en doce reales

109 Una ballena $s$ encarnada antigua en un peso $1 \mathrm{p}$.

110 Un delantal de bretaña 9 con puntas de En 1 peso a la pita $\mathbf{1 0}$ en tres pesos dicha

T Bombacha. Martín Alonso: Enciclopedia del Ldioma: "Pantalón, calzón bombacho."

8 Ballena "Diccionario de autoridades: "Se llama... el ajustador que traen las mujeres, que por otro nombre se llama cotilla. Dícese ballena, porque se compone y hace de las barbas de este pescado."

9 Bretaña Diccionario de autoridades: "Cierto género de lienzo fino, que se fabrica en la provincia de Bretaña, de quien tomó el nombre. Hiay dos especies, una ancha y otra más angosta."

10 Pita. Diccionario de autoridades: "Planta que vino de Indias, algo semejante 
111 Una toca de vendillas verdes con puntas y En 1 peso a la encajes de seda cruda, en tres pesos dicha

\section{Cuatro antepuertas 11 de sarga encarnada} con sus goteras, 12 en diez pesos

113 Una cortina grande de sarga encarnada, servida, en cuatro pesos

114 Diez y seis cojines de damasco encarnado el A José de Fuentes más y el otro listado con sus fundas de... en 48 pesos, esta. [ilegible] llenos de lana, en ochenta pesos ban ya viejos

115 Una alfombra de cuatro varas de largo y Al dicho en 22 dos y medio de ancho, en treinta y dos pesos pesos, estaba ya vieja

116 Dos tapetillos ordinarios muy viejos, en un peso

117 Un vestido de raso negro con dos pares de A Miguel Barra- calzones, ropilla margas 13 armador 14 de gán en 32 pesos, raso morado y capa de páno de Holanda por estar ya muy con sus encajes, todo nuevo, en sesenta pesos servido

118 Un armador de lana de China azul, viejo, en dos pesos

119 Un coletillo ${ }^{15}$ de ante de cabrilla de solapa, Al dicho en 8 pe- en dos pesos sos

a la higuera de tuna Arroja del tronco unas hojas largas y gruesas, que rematan cn una punta muy aguda y dura, y dentro de ellas se cría una especie de hierba, de la cual seca, se hace el hilo que llaman de pita."

11. Antepuertas. Diccionario de autoridades: "La cortina, paño o cancel que se pone delante de una puerta o por abrigo o por mayor decencia, para que desde afuera no se registre el aposento."

12 Goteras. Diccionario de autoridades: "Significa... 1a caída de la tela en los doseles, camas y otras cosas semejantes, pendiente del que llaman cielo, y le sirve de adomo y cenefa."

13 Margas. Diccionario de autoridades: "Se llama cierta tela de estopa bastísima, que sirve para hacer sacas de lana y otras cosas semejantes."

14 Armador, Diccionario de autoridades: "Cierta especie de jubón que se solia hacer de ante, y aforrar o cubrir por encima con tela o seda por gala. Parece se pudo decir porque armaba bien al talle, o porque asentaba bien sobre él las armas, o porque en algún modo exa defensa del cuerpo."

15 Coleto. Diccionario de autoridades: "Vestidura como casaca o jubón que se 
120 Unas fundas de sayesaya encarnadas bordaAl dicho en 3 pe. das, de seda verde, en seis pesos sos ya muy servidos

121 Dos carabinas guarnecidas de... [ilegible] A Nicolás de Soto con sus fundas de vaqueta, en treinta pesos en 20 pesos

122 Una fresada de cabrilla encarnada, en doce A Miguel Barra- pesos gán en 6 pesos

123 Otro de algodón listado viejo, en cuatro Al dicho en 2 pe- pesos sos

124 Tres colchones listados de azul y blanco lleAl dicho en 12 nos de lana, a siete pesos cada uno pesos, ya muy ser. vidos

125 Una sobrecama de felpa rosada listada de A Juan Cancino blanco, en treinta y cinco pesos en 18 pesos, ya vieja

126 Un tapetillo de felpa de colores ya raído, Al dicho en 3 pe- en seis pesos sos

127 Dos, digo una colchita de ... [ilegible] en Al dicho en 1 tres pesos peso

128 Una tabla de mantel 16 alemanisco 17 con cuatro servilletas, en dos pesos

129 Dos toallas alemaniscas, a peso cada una

hace de piel de ante, búfalo $u$ de otro cuero. Los largos como casacas tienen mangas, y sirven a los soldados para adorno y defensa, y los que son de hechura de jubón se usan también para la defensa y abrigo."

16 Tabla de maniel. Diccionario de autoridades: "El paño de lino que se tiende, y con que se cubre la mesa, para comer."

17 Alemanisco. Diccionario de autoridades: "Cosa perteneciente a Alemania, de cuyo nombre está formada esta palabra; la cual en el uso de nuestra lengua se apropia a cierto género de manteletía fabricada y tejida a cuadritos, algo mayores que la que llaman de gusanilio; y porque este tejido vino la primera vez de Alemania, se le dio el epíteto de Alemanisco." 
130 Seis paños de quapascle, 18 fruteros, en dos pesos

131 Una cama de damasco verde con flecos de A Salvador Martí- oro y caídas bordadas, con cuatro cortinas nez en 20 pesos, y rodapiés, vieja en treinta pesos muy vieja

132 Doce pañuelos falderos de sayesaya encarA María Teresa nada, guarnecidos de encaje blanco, en doce en 6 pesos, muy pesos viejos

133 Doce pañuelos pequeños de lo mesmo a cua. A la dicha en 2 tro reales pesos

134 Cinco pañuetos falderos de liencecillo azul A la dicha en 2 deshilados de pita amarilla con punta de lo pesos mesmo, en cuatro pesos

135 Una toalla blanca deshilada de pita ama. A la dicha en 1 rilla, en cuatro pesos peso 4

136 Otra dicha blanca labrada de seda... [ileA la dicha en 1 gible], en tres pesos peso

137 Iten un vestido de capuchola de Castilla, A Miguel Barra. negro, ropilla, dos pares de calzones y argán en 6 pesos, ya mador, en diez y seis pesos viejo

138 Otro vestido, ropilla y calzón de pelo de Al dicho en 2 pe- camello negro, en seis pesos sos, muy viejo

139 Una bombacha de pelo de camello de color Al dicho en 3 pe- y calzón de paño de Holanda, raído, seis sos pesos

18 Cuapascle Cecilio A Robelo: Diccionario de aztequismos o sea jardin de las raices aztecas. Palabras del idioma náhuatl, azteca o mexicano, introducidas al idioma castellano bajo diversas formas (contribución al diccionario nacional), $3 \mathrm{a}$. ed,. México, Ediciones Fuente Cultural, s/f (Colección Daniel). Raíces: Cuauhpactli, de cuauhuitl que significa árbol, y pachtli que significa heno, o sea "Heno de árbol" Explica Robelo lo siguiente: "Úsase este aztequismo, no para expresar el vegetal que significa, sino como adjetivo, para expresar el color leonado, que se acerca al rojo como la lama y el heno tiernos de los árboles." 
140 Tres capas negras viejas: dos de... [ilegible] Al dicho en 2 pe- y una de sarga, en seis pesos sos, todas ya muy viejas

141 Una bombacha de felpa negra vieja en seis Al dicho en 2 pe- pesos $\operatorname{sos}$

142 Tres varas de estameña 19 a seis reales la vara

143 Un bonete, en cuatro tomines

144 Un aderezo de espada y daga de alcaparro. nes ${ }^{20}$ con la daga quebrada, en cuatro pesos

145. Una silla jineta bordada de seda verde con A Francisco Mal- sus cabezadas, con su estribera de medio donado en 18 pe- lazo, nueva, en veinte y cinco pesos sos
Al dicho en 1 pesos
146 Otra silla brida negra muy vieja, en tres peso

147 Iten tres barretas chicas de fierro que valuó de consentimiento de las partes, Manuel de Peralta, real y medio libra, y pesaron cuarenta libras

148 Un rodadillo 21 nuevo de fierro, en tres pesos

149 Otro dicho viejo, en cuatro reales

150 Tres asadones: uno grande y dos pequeños, en dos pesos

151 Dos palas viejas, en seis reales ambas

152 Dos sierras, en dos pesos

19 Estameña. Diccionario de autoridades: "Tejido de lana asi dicho por ser la urdimbre y trama toda de estambre."

20 Alcaparrones. Diccionario de autoridades: "...un género de guarnición de espada que se usaba antiguamente."

21 Rodallo. Martín Alonso: Enciclopedia del idioma: "Batidera con mango largo para juntar las brasas y cenizas del horno; rodillo." 
153 Otra dicha grande, en tres pesos $3 \mathrm{p}$

154 Otra más mediana, en doce reales 1 p. 4

155 Otra dicha, en diez reales 1 p. 2

156 Otra sierra pequeña, en un peso $1 \mathrm{p}$.

157 Veinte y cinco cubos, a cuatro reales unos con otros

158 Otras dos barretas: una grande y otra mediana, que pesaron veinte libras, que tasan a real y medio libra

159 Una barrena de bóvedas, que pesó tres libras, que tasa a real y medio libra

$\mathrm{Y}$ en ese estado se quedó dicho inventario para lo proseguir y los bienes en él contenidos, quedaron en poder del dicho don Antonio de Quiñones como el albaciea y tenedor de ellos, de que se dio por entregado y se hizo cargo para dar cuenta de ellos a que obligó sus bienes en forma y lo firmó con dicho curador y avaluadores excepto el dicho Pedro de los Reyes que dijo no saber, a su ruego lo firmó un testigo, siéndolo Lorenzo de Aragón, el Bachiller don Carlos de Salinas presbítero y Juan Pérez, vecinos de México. Bachiller don Antonio de Quiñones Osorio. Juan de Monzón. Manuel de Peralta Gregorio Pardo. Por testigos Bachiller don Carlos de Salinas Galindo. Ante mí Juan Díaz de Rivera, escribano real y público.

\section{[AI margen]}

\section{Inventario}

En la ciudad de México, a quince días del mes de febrero de mil y seiscientos y noventa y cinco años, ante mí, el escribano y testigos, el Bachiller don Antonio de Quiñones, presbítero, albacea y tenedor de bienes de Juan Montero, y presente Juan de Monzón, curador ad liten de María Montero de Aguilera, menor hija y heredera de dicho difunto, y Manuel de Peralta, persona inteligente en todas materias, tasador nombrado por las partes para la tasación de las casas y menudencias que restan por inventariar, a quienes doy fe conozco, se prosiguió a dicho inventario y apreció en la manera siguiente

Número 160 Primexamente, pone por inventario un mula retinta de camino, vieja con heno, silla gerónima de vaqueta leonada, con estribos y freno maltratado, que se avaluó en treinta pesos

161 Dos mecheros de seis candeleros de labor, plateados, a tres pesos 
162 Cinco platillos y un platón de latón de Castilla, en cuatro pesos

163 Dos calderetas, 22 un jarrito batidor [?] y un jarro para beber agua, en dos pesos

164 Cinco candeleros medianos y dos blandocillos de cobre, todos en tres pesos

165 Un... [ilegible] con su mano, en doce reales

166 Dos... [ilegible] latón viejas, en doce reales

167 Una jeringa, en un peso

168 Un candado de latón medianito, en dos pesos

169 Una azuela 23 sin armar y un garabato, 24 en cuatro reales

170 Veinte libros de diferentes historias y tratados, en ocho pesos

171 Seis arrobas y tres libras de fierro viejo y nuevo en diferentes piezas que se avaluó en real y medio libra, que hacen

Con lo cual se acabó dicho inventario y aprecio, y todos los bienes en él contenidos quedaron en poder del dicho Bachiller don Antonio de Quiñones Osorio, como tal albacea y tenedor de bienes de dicho difunto, de que se hizo cargo y dio por entregado, renuncia leyes de la entrega y su prueba y se obligó a dar cuenta de todos a que obligó los suyos en forma, y juró in verbo sacerdoti, puesta la mano en el pecho, no saber de otros bienes de dicho ditunto, con protestación que hace de que cada y cuanto que a su noticia vengan, los pondrá por inventario, y lo firmó con dicho curador y tasador, siendo testigos el Bachiller don Carlos de Salinas, presbítero, Nicolás de la

22 Calciereta. Martín Alonso: Enciclopedia del Idioma: "Salamanca. Caldero pequeño de forma circular provisto de un asa por la cual se cuelga a la correa de la mochila."

23 Azuela. Diccionario de autoridades: "Instrumento corto, no muy grande, hecho de madera, que tiene en el extremo un hierro doble, extendido, acerado y atilado, que sirve para labrar y desbaratar la madera. Es voz de la carpintería..."

24 Garabato. Diccionario de autoridades: "Instrumento de hierro, cuya punta vuelve hacia arriba en semicírculo. Sirve para colgar y sostener algunas cosas, o para asirlas o agarrarlas. Sale del nombre garra, quitada una $r$ para suavizar la pronunciación." 
Marcha y Juan del Llano, presentes. Bachiller don Antonio de Quiñones Osorio, Juan de Monzón. Manuel de Peralta. Ante mí, Juan Díaz de la Rivera, escribano real y público.

\section{[Al margen]}

\section{Inventario}

En la ciudad de México, a diez y ocho días del mes de febrero de mil y seiscientos y noventa y cinco años, ante mí, el escribano y testigos, el Bachiller don Antonio de Quiñones Osorio, presbitero, albacea y tenedor de bienes de Juan Montero, maestro de arquitectura y aparejador mayor que fue de la fábrica material desta Santa Iglesia que doy fe conozco, en conformidad de la protesta que hizo de que cada y cuando que a su noticia veniesen bienes del dicho difunto lo pondría por inventario, en presencia de Juan de Monzón, curador ad liten de María Montero de Aguilera, menor hija y heredera de dicho difunto, a quien asimismo doy fe conozco, lo hace en Ia manera siguiente

Número 172 Primeramente, pone por inventario sesenta
pesos de oro común en reales, por tantos,
que entregó Antonio de la Gruz, mulato
esclavo de dicho difunto por su libertad,
conforme a las cláusulas del testamento y
cobdicilio de dicho difunto

173 Iten, declara que habiendo ocurrido al señor Chantre don Manuel de Escalante y Mendoza, mayordomo y tesorero y administrador de la fábrica real de esta Santa Iglesia Catedral y mostrándole el testamento y cobdicilio de dicho Juan Montero, donde declara lo que se le debe por razón de tal aparejador mayor, a razón de doce reales todos los días, entrando los festivos, dejando a la conciencia y cristiano proceder de Su Señoría, el ajuste de esta dependencia, dijo no deberle cosa ninguna por razón de ello como parecía del recibo que tenía en su poder y que reconocidos los libros y papeles y ajustada la cuenta se le debiese algo, se lo satisfaría, por cuya causa no pone por inventario cosa alguna ni le hace cargo de nada, y si en algún tiempo hubiere algo, lo manifestará, y así lo declara para que conste
$60 \mathrm{p}$.

Con lo cual acabó dicho inventario y se hace cargo de dichos sesenta pesos para dar cuenta con los demás debajo de dicha protesta, y lo firmó con dicho curador, siendo testigos el Bachiller don Carlos de Salinas, presbítero, Diego 
Díaz de la Rivera y Manuel Maldonado, vecinos de México. Bachiller don Antonio de Quiñones Osorio Juan de Monzón. Ante mí, Juan Díaz de la Rivera, escribano real y público.

Según que lo referido más largamente de dicha petición, auto... [ilegible] e inventario y aprecios que quedan en el archivo de mi cargo a que me remito y para que conste dicho pedimento y mandamiento, doy el presente en la ciudad de México a trece días del mes de marzo de mil y seiscientos y noventa y nueve años, y va el primer pliego en papel del sello segundo de este año y el intermedio común, siendo testigos Juan Díaz de Rivera, Pedro Nolasco de Reina y Nicolás Gutiérrez, vecinos de México, presentes. [Testaduras].

En testimonio de verdad hago mi signo

Juan Díaz de Rivera

Escribano Real y Público

AGN (Bienes Nacionales: 381, doc, 18) 